\title{
Novel removal of Anthracene from oil-contaminated water by synthesized modified magnetic nano-particles
}

\author{
A. Torabian*, H. Ahmad-Panahi**, G.R. Nabi-Bidhendi*, N. Mehrdadi
}

Faculty of the Environment, University of Tehran, 25 Ghods St., Enghelab Ave, Tehran, Iran Azadeht4@yahoo.com

Department of Chemistry, Islamic Azad University, Central Tehran Branch, Payambar Complex, Shahrak-e Gharb, Tehran, Iran

Panahi20002000@yahoo.com

Faculty of the Environment, University of Tehran, 25 Ghods St., Enghelab Ave, Tehran, Iran

Gnabi@ut.ac.ir

Faculty of the Environment, University of Tehran, 25 Ghods St., Enghelab Ave, Tehran, Iran

nmehrdadi@ut.ac.ir

\begin{abstract}
Novel magnetic nanoparticles (MNPs) modified with (3-mercaptopropyl)-trimethoxysilane (MPTMS), grafted with allyl glycidyl ether and coupled with beta naphthol, were prepared for removal of anthracene in aqueous solutions. The grafted MNPs were characterized by transmission electron microscopy (TEM), infrared spectroscopy (FT-IR) and thermogravimetric analysis (TGA). The modified MNPs contributed to enhancement of the adsorption capacity and were prepared by co-precipitation. The modified MNPs were characterized by TEM, FT-IR and TGA and the adsorption and kinetic behavior of anthracene on the modified MNPs was examined. It was shown that the nano-adsorbent optimized adsorption capacity is at $\mathrm{pH}$ 7. Three kinetics models: pseudo-first-order, pseudo-second-order, and intraparticle diffusion were used to investigate the adsorption mechanism of the anthracene onto the modified MNPs. The best fit was obtained for the pseudo-second-order model. The synthesized nano adsorbent can be considered as a new method for anthracene adsorption in contaminated water with the benefit of fast removal by applying a magnetic field.
\end{abstract}

\section{Keywords}

Anthracene; Magnetic nanoparticles; Kinetic study; Modification

\section{Council for Innovative Research}

Peer Review Research Publishing System

Journal: Journal of Advances in Chemistry

Vol. 10, No. 2

editorjaconline@gmail.com

www.cirjac.com 


\section{INTRODUCTION}

Anthracene (ANT) is one of a group of chemicals called polycyclic aromatic hydrocarbons (PAHs). PAHs are often found in groups of two or more; they can exist in over 100 different combinations, but the most common are treated as a group of 15. PAHs are found naturally in the environment but can also be man-made. ANT can vary in appearance from a colorless to pale yellow crystal-like solid. ANT, like other PAHs, are created when products like coal, oil, gas, and garbage are burned, but the burning process is not complete. ANT is used to make dyes, plastics, pesticides, smoke screens and scintillation counter crystals. Exposure of the skin to contaminated soil or products like heavy oils, coal tar, roofing tar, or creosote where PAHs have been found can have adverse health effects. Creosote is an oily liquid found in coal tar and is used to preserve wood. Once in the body, ANT can spread and target fat tissues and organs, including the kidneys and liver.

Recent interest in nano-materials comes from their physical and magnetic properties, especially their nano size. Using the magnetic effect of certain types of nano-particles has simplified the process of separating, removing/isolating chosen components from a sample solution. Nano-sized magnetic iron oxide particles have been studied as a new adsorbent with a large surface area and small diffusion resistance [1] for the separation and removal of chemical species such as metals [1-7], dyes [8-10], and gases [1]. Considerable attention has been paid to the combination of organic groups and inorganic magnetic Fe3O4 particles at the nano-sized level because of their high specific surface area and the absence of internal diffusion resistance compared to traditional micron-sized supports [11, 12]. It is easy to change the chemical characteristics of the adsorbent surface by chemical modification of the surface. Surface-modified absorbents can show higher attraction to some substances.

In this study, MNPs were synthesized and grafted with functional monomer and coupled with beta-naphthol. The coupledgrafted MNPs (CGMNPs) showed a high adsorption capacity for ANT and could be easily separated out from the sample solution using an external magnetic field. This research evaluated the adsorption potential of CGMNPs for ANT. The kinetic adsorption studies were processed to understand the adsorption mechanism of ANT onto GCMNPs. Kinetic data was used to calculate the rate at which the object particle was removed from the aqueous solution

\section{MATERIALS AND METHODS}

\section{Materials}

1, 4-Dioxane, 2-naphthol, $\mathrm{NaCl}, \mathrm{C} 2 \mathrm{H} 5 \mathrm{OH}, \mathrm{CH} 3 \mathrm{COOH}, \mathrm{FeCl} 2.4 \mathrm{H} 2 \mathrm{O}, \mathrm{FeCl} 3.6 \mathrm{H} 2 \mathrm{O}, \mathrm{NH} 4 \mathrm{OH}, \mathrm{C} 14 \mathrm{H} 10, \mathrm{C} 16 \mathrm{H} 10$ were purchased from Merck (Darmstadt, Germany). N, N-Dimethylformamide (DMF), 3-mercaptopropyltrimethoxysilane (MTPMS), allyl glycidyl ether (AGE) and 2, 2-azoisobutyronitrile (AIBN), were purchased from Aldrich (Steinheim, Germany). Anthracen was purchased from Fluka Chemical (Buchs, Switzerland); the molecular structure of ANT is shown in Fig. 1. All the reagents were of analytical grade and used without further purification. The stock solution $(2000 \mathrm{mgL}-1)$ of ANT was prepared by dissolving appropriate amounts of ANT in distilled water. For $\mathrm{pH}$ adjustment of the solution, $10 \mathrm{ml}$ of $0.1 \mathrm{M}$ acetic acid-acetate buffer $(\mathrm{pH} 3-6.5)$ was used wherever required

\section{Synthesis and surface grafting of magnetite nanoparticles}

The MNPs were prepared using chemical co-precipitation by adding ammonia drop-wise to a $\mathrm{Fecl} 2.4 \mathrm{H} 2 \mathrm{O}$ and $\mathrm{FeCl} 3.6 \mathrm{H} 2 \mathrm{O}$ solution while injecting nitrogen gas for $30 \mathrm{~min}$. The reaction was carried out at $80^{\circ} \mathrm{C}$ for $2 \mathrm{~h}$. While the ammonia was added, the color of the solution went from its original brown to dark black, indicating the preparation of MNPs.

The second step was modification of the MNPs. The washed MNPs were dried for $24 \mathrm{~h}$ and then silylated using an anhydrous solution of $5 \%$ MPTMS in 1, 4-dioxane. The reaction was done in a 1-necked round-bottom flask (equipped with a condenser) at the solution boiling point for approximately $24 \mathrm{~h}$. The modified MNPs (MMNPs) were washed several times with 1, 4-dioxane and dried. The MMNPs and MPTMS were transferred to a degassed graft-polymerization solution containing ethanol as a solvent, AGE, and AIBN as an initiator for $6 \mathrm{~h}$ at $70^{\circ} \mathrm{C}$. The grafted MMNPs (GMMNPs) were then separated out using a magnetic field, washed, and dried.

The final step was coupling 2-naphthol onto the GMMNPs. This reaction was done by adding the GMMNPs and 2 naphthol dissolved in DMF into a temperature-controlled reactor. The reaction was completed in $8 \mathrm{~h}$ at room temperature. The coupled GMMNPs were separated out using a magnetic field, washed, and dried. The aromatic rings of 2-naphthol enabled the adsorption by $\pi-\pi$ reactions between benzo(a)pyrene and coupled-grafted-modified MNPs (CGMMNPs). A complete schematic of the synthesis is shown in Fig. 2.

The new CGMMNPs applied as nano-adsorbents were characterized using FT-IR and scanning electron microscopy (TEM).

\section{Adsorption studies}

The adsorption of ANT by the CGMMNPs (as a magnetic nano-adsorbent) was studied by batch equilibrium in an aqueous solution. For the adsorption experiments, stock aqueous solutions of ANT were prepared by dissolving the proper amount of ANT in twice-distilled water. The initial stock solution was $2000 \mathrm{mgl}-1$, and the secondary stock solution was $0.8 \mathrm{mgl}-1$. The effect of $\mathrm{pH}$ was studied for a range of 4 to 8 . For each experiment, $0.02 \mathrm{~g}$ of adsorbent was poured into a beaker and mixed with $10 \mathrm{ml}$ of secondary solution. The $\mathrm{pH}$ values were adjusted to the desired value in range of the buffer solutions $(0.01 \mathrm{M}$ acetate and/or $0.01 \mathrm{M}$ phosphate). The final solution was shaken for $10 \mathrm{~min}$ at room temperature. Afterward, the magnetic nano-adsorbents were removed using a magnetic field and the remaining supernatant ANT concentration was 
measured using HPLC (Agilent 1100 series). The amount of ANT at equilibrium qe (mg g-1) on the CGMMNPs s was calculated as:

(1) $q e=(\mathrm{Co}-\mathrm{Ce}) \mathrm{V} / \mathrm{W}$

Where $\mathrm{CO}$ and $\mathrm{Ce}(\mathrm{mg} / \mathrm{l})$ are the initial and equilibrium ANT concentrations, respectively, $\mathrm{V}$ is the volume of the ANT solution, and $\mathrm{W}(\mathrm{g})$ is the mass of the adsorbent.

The kinetic study of ANT adsorption onto CGMMNPs was done by applying the same experimental procedure described above. Different beakers containing ANT solution and 0.02 of nano-adsorbent were shaken for different time intervals; as in previous experiments, the optimum $\mathrm{pH}$ was 7. Adsorption was determined by:

(2) $q t=(C O-C t) V / W$

Where $\mathrm{CO}$ and $\mathrm{Ct}(\mathrm{mg} / \mathrm{l})$ are the ANT concentrations initially and at each time interval, respectively, $V$ is the volume of the ANT solution, and $\mathrm{W}(\mathrm{g})$ is the mass of the nano-adsorbent.

\section{RESULTS AND DISCUSSION}

\section{The characterization of copolymer-grafted magnetic nanoparticles}

The CGMMNPs were characterized by transmission electron microscopy (TEM), infrared spectroscopy (FT-IR) and thermogravimetric analysis (TGA). The FT-IR spectrum for the CGMMNPs was compared with the raw MNPs as well as FT-IR: ( $\mathrm{NaCl}, \mathrm{cm}-1) 3779.8(\mathrm{OH}), 1627(\mathrm{C}=\mathrm{O}), 1450$ (aromatic cycle), 3051.53 (aromatic $\mathrm{C}-\mathrm{H})$ and $1000(\mathrm{C}-\mathrm{O})$. The presence of an aromatic group in the FT-IR spectrum of the CGMMNPs indicates that coupling of the 2-naphthol was performed successfully. The TGA of the unmodified MNPs indicated that weight loss up to $120^{\circ} \mathrm{C}$ was caused by water molecule desorption from the surface; after $200^{\circ} \mathrm{C}$, the weight remained constant.

GMNPs, however, showed completely different thermal behavior. Weight loss up to $200^{\circ} \mathrm{C}$ was caused by the water molecules in the grafted MNPs and the weight loss at 220 to $500^{\circ} \mathrm{C}$, was because of the decomposition and desorption of the polymeric matrix Fig. 3. These results demonstrate the formation of CGMMNPs. The FT-IR spectrum and TGA confirmed the structure of the grafted polymer. TEM was used to examine the external surface of the CGMMNPs. As shown in Fig. 4, the particles were spherical with a rough surface and the particle size was $15-40 \mathrm{~nm}$.

\section{Effect of pH on ANT adsorption}

The effect of $\mathrm{pH}$ was studied for a range of 4-8 Fig. 5. The studies showed that $\mathrm{pH}$ played a critical role in the adsorption process. An appropriate $\mathrm{pH}$ value increased the adsorption effectiveness and decreased interference with the matrix. The adsorption of ANT in solution decreased as the $\mathrm{pH}$ of the aqueous solution increased from 4 to 5 . At $\mathrm{pH}=7$, optimum adsorption was achieved, suggesting a neutral $\mathrm{pH}$ for adsorption. At this $\mathrm{pH}$, no precipitation occurred; $\mathrm{pH}$ values above 8 were not considered because of their effect on CGMMNP structure.

\section{Adsorption kinetics}

Fig. 6 shows the adsorption kinetics of ANT onto CGMMNPs. The kinetic study indicated that 10 min was sufficient for complete adsorption. The profile of ANT uptake by the CGMMNPs showed good accessibility of the active sites on the nano-absorbent surface. The adsorption kinetics of ANT onto the CGMMNPs was done using pseudo-first-order and pseudo-second-order kinetic equations. The pseudo-first-order equation is:

(3) $\log (q e-q t)=\log q e-k 1 t / 2.303$

Where qe and $\mathrm{qt}(\mathrm{mg} / \mathrm{g})$ are the amount of adsorbed ANT at equilibrium and at time $\mathrm{t}$, respectively, and $\mathrm{k} 1$ is the rate constant of the pseudo-first-order (1/min). As shown in Fig. 7, a straight line resulted from the plot of log (qe-qt) versus $t$ where $\mathrm{k} 1$ is the line slope. Table 1 shows the calculated and experimental qe and R2 correlations.

The pseudo-second-order equation is:

(4) $t / q t=1 / k 2 q e 2+t / q e$

In this equation, qe and $\mathrm{qt}(\mathrm{mg} / \mathrm{g})$ are the amount of ANT adsorbed onto the CGMMNPs at equilibrium and at time $t$, respectively, and $k 2$ is the rate constant of the pseudo-second-order ( $\mathrm{g} / \mathrm{mg} \mathrm{min}$ ). By plotting $\mathrm{t} / \mathrm{qt}$ versus $\mathrm{t}$, a straight line results (Fig. 8) where qe and k2 are the slope and intercept of this line, respectively. The values of $k 2$, the calculated and experimental qe, and the correlation coefficients (R2) are shown in Table 1.

Because of the probability of intra-particle diffusion, the intra-particle diffusion model was used to evaluate the diffusion mechanism of adsorption. The model is represented as:

(5) $q \mathrm{t}=\mathrm{kpt} 0.5+\mathrm{C}$

In this equation, $\mathrm{C}$ is the intercept and $\mathrm{kp}$ is the slope of intra-particle diffusion ( $\mathrm{mg} / \mathrm{g} \mathrm{min} \mathrm{0.5).} \mathrm{From} \mathrm{the} \mathrm{plot} \mathrm{of} \mathrm{qt} \mathrm{versus} \mathrm{t}$, a straight line results (Fig. 9). The values of kp, C, and R2 are shown in Table 1. If the line does not pass through the origin, it means that intra-particle diffusion is not the only rate-limiting process, and the relationship between qt and t0.5 is not linear. Other rate-controlling steps can be explained by the boundary layer effect. As seen in Table 1 the calculated qe value for the pseudo-second-order kinetics agrees with the experimental qe value and its correlation coefficient was greater than 0.99 This shows that the pseudo-second-order kinetics model well described the adsorption kinetics.It can be 
concluded that this kind of grafted magnetic adsorbent in low amounts shows selectivity for the ANT. Compared with the conventional adsorption process, the magnetic separation method has advantages such as ease of operation, cost effectiveness, high selectivity, and rapid separation.

\section{CONCLUSION}

A method is introduced in this study for graft polymerization of MNPs and coupling it with an aromatic compound as a novel adsorbent. The nano-adsorbent showed good potential for fast removal of PAHs from large sample volumes and possessed advantages such as of high adsorption capacity and high chemical stability. The optimized capacity was achieved at $\mathrm{pH} 7$ and the equilibrium time was $10 \mathrm{~min}$.

On the basis of Langmuir isotherm analysis, the monolayer adsorption capacity was determined to be $4.17\left(\mathrm{mg} \mathrm{g}^{-1}\right)$ at $20^{\circ} \mathrm{C}$. Pseudo-first-order, pseudo-second-order, and intra-particle diffusion were kinetic models used to determine the adsorption mechanism of ANT onto CGMMNPs. The best fit was achieved by the pseudo-second-order model; therefore, this type of modified nanoparticle can be introduced as a low-cost and effective adsorbent for ENR adsorption from aqueous solutions.

\section{ACKNOWLEDGMENTS}

The authors appreciate the support provided University of Tehran,

\section{REFERENCES}

[1] Liao $\mathrm{MH}$, Chen D. Fast and efficient adsorption/desorption of protein by a novel magnetic nano-adsorbent Biotechnology Letters 2002;24:1913-7.

[2] Faraji M, Yamini Y, Rezaee M. Extraction of trace amounts of mercury with sodium dodecyle sulphate-coated magnetite nanoparticles and its determination by flow injection inductively coupled plasma-optical emission spectrometry. Talanta 2010;81:831-6.

[3] Huang C, Hu B. Silica-coated magnetic nanoparticles modified with Y-mercaptopropyltrimethoxysilane for fast and selective solid phase extraction of trace amounts of $\mathrm{Cd}, \mathrm{Cu}, \mathrm{Hg}$, and $\mathrm{Pb}$ in environmental and biological samples prior to their determination by inductively coupled plasma mass spectrometry. Spectrochimica Acta Part B: Atomic Spectroscopy 2008;63:437-44.

[4] Macdonald J, Kelly J, Veinot J. Iron/Iron Oxide Nanoparticle Sequestration of Catalytic Metal Impurities from Aqueous Media and Organic Reaction Products. Langmuir 2007;23:9543-5.

[5] Mayoa JT, Yavuza C, Yeanb S, Congb L, Shipleyb H, Yua W, et al. The effect of nanocrystalline magnetite size on arsenic removal. Science and Technology of Advanced Materials 2007;8:71-5

[6] Uheida A, Alvarez G, Björkman E, Yu Z, Muhammed M. Fe3O4 and y -Fe2O3 nanoparticles for the adsorption of Co2+ from aqueous solution. Journal of Colloid and Interface Science 2005;298:501-7.

[7] Wang L, Yang Z, Gao J, Xu K, Gu H, Zhang B, et al. A Biocompatible Method of Decorporation: BisphosphonateModified Magnetite Nanoparticles to Remove Uranyl lons from Blood. Journal of the american chemical society 2006;128:13358-9.

[8] Chang Y, Chen D. Adsorption Kinetics and Thermodynamics of Acid Dyes on a Carboxymethylated ChitosanConjugated Magnetic Nano-Adsorbent. Macromolecular Bioscience 2005;5:254-61.

[9] Faraji M, Yamini Y, Saleh A, Rezaee M, Ghambarian M, Hassani R. A nanoparticle-based solid-phase extraction procedure followed by flow injection inductively coupled plasma-optical emission spectrometry to determine some heavy metal ions in water samples. Analytica Chimica Acta 2010;659:172-7.

[10] Yang N, Zhu S, Zhang D, Xu S. Synthesis and properties of magnetic Fe3O4-activated carbon nanocomposite particles for dye removal. Materials Letters 2008;62:645-7.

[11] Goswamia R, Debb P, Thakurc R, Sarmaa KP, Basumallickd A. Removal of As(III) from aqueous solution using functionalized ultrafine iron oxide nanoparticles, . Separation Science and Technology 2011;46:1017-22.

[12] Li Z, Sun Q, Gao M. Preparation of Water-Soluble Magnetite Nanocrystals from Hydrated Ferric Salts in 2 Pyrrolidone: Mechanism Leading to Fe3O4. Angewandte Chemie International Edition 2004;44. 
<smiles>c1ccc2cc3ccccc3cc2c1</smiles>

Fig 1:Anthracene moleculare structure
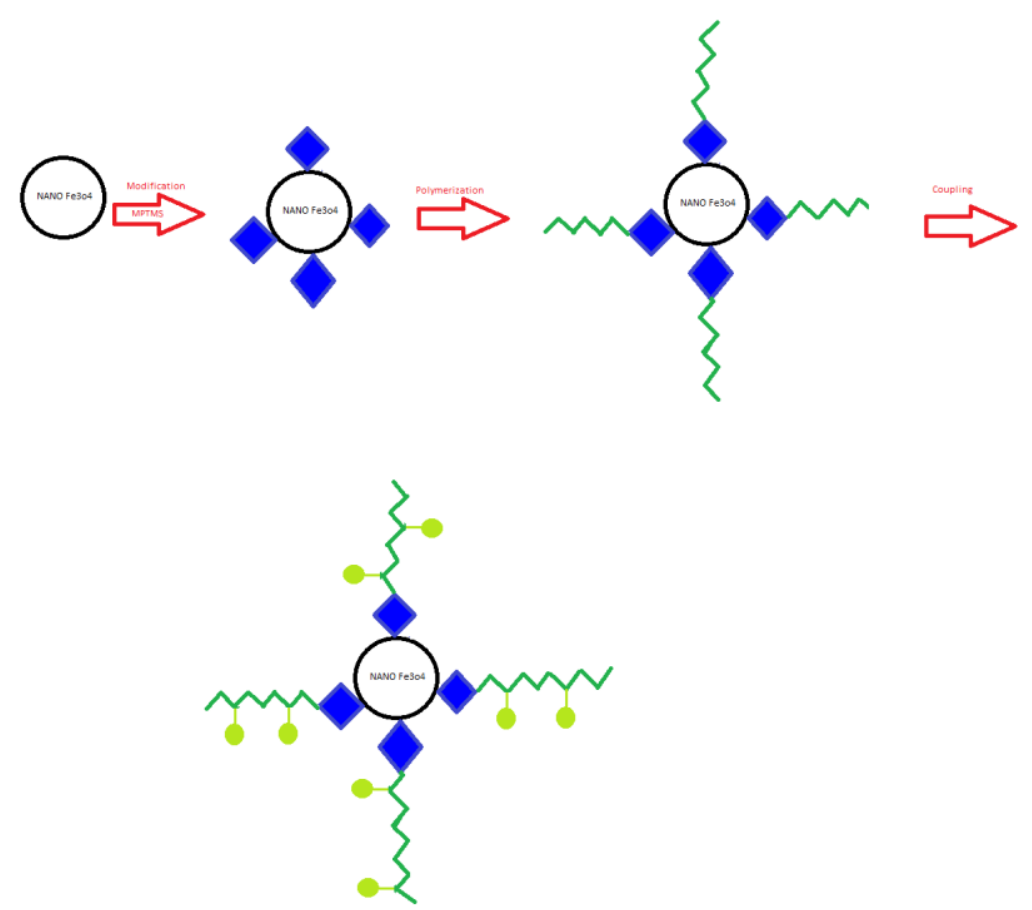

Fig 2: Schematic presentation of sylation, graft polymerization and coupling of grafted magnetic nano particles 


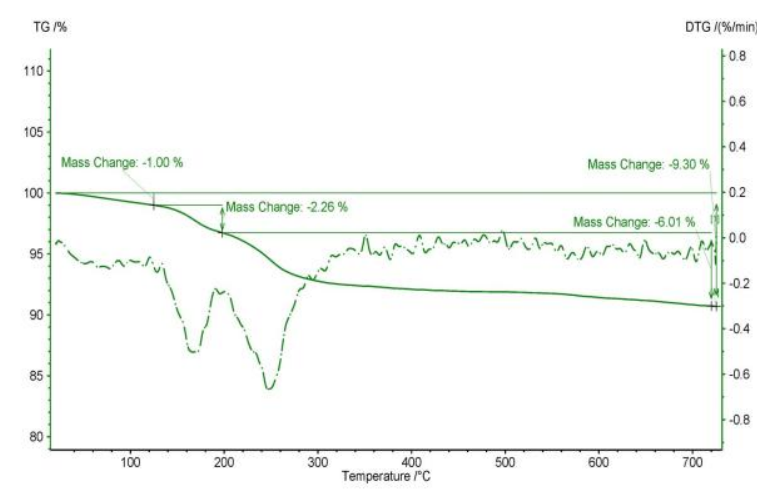

a

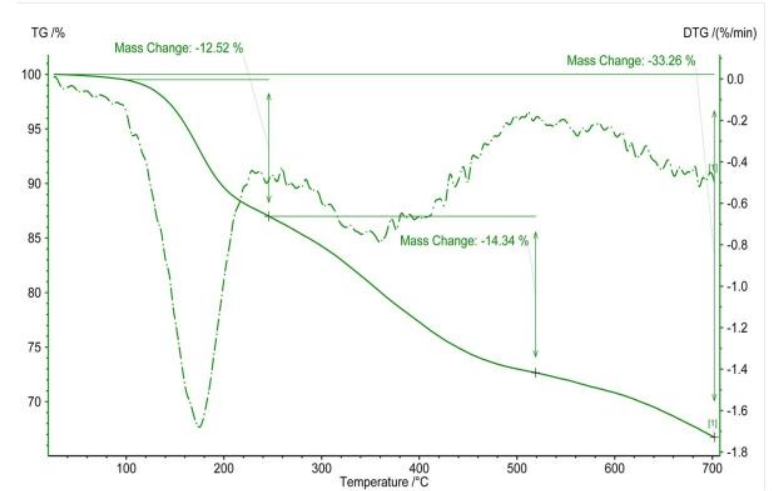

C Fig. 3. Thernogravimetric analysis of MNPS (a), modified MNPs (b), gratted MNPs (c) CGMMNPs (d)

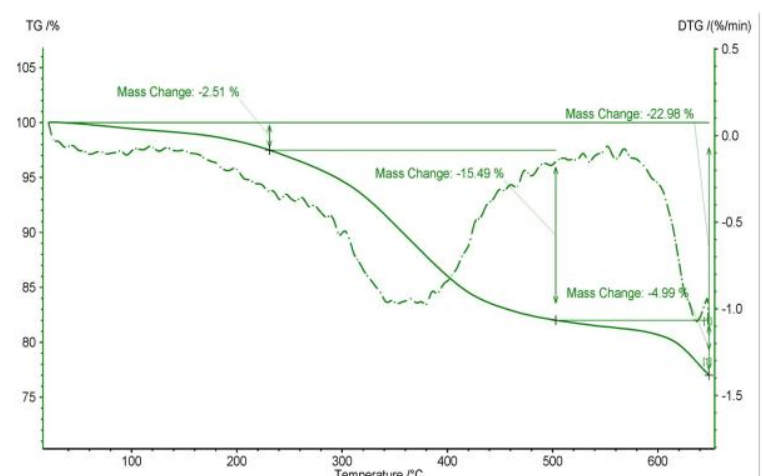

d

Fig 3:Thermogravimetric analysis 


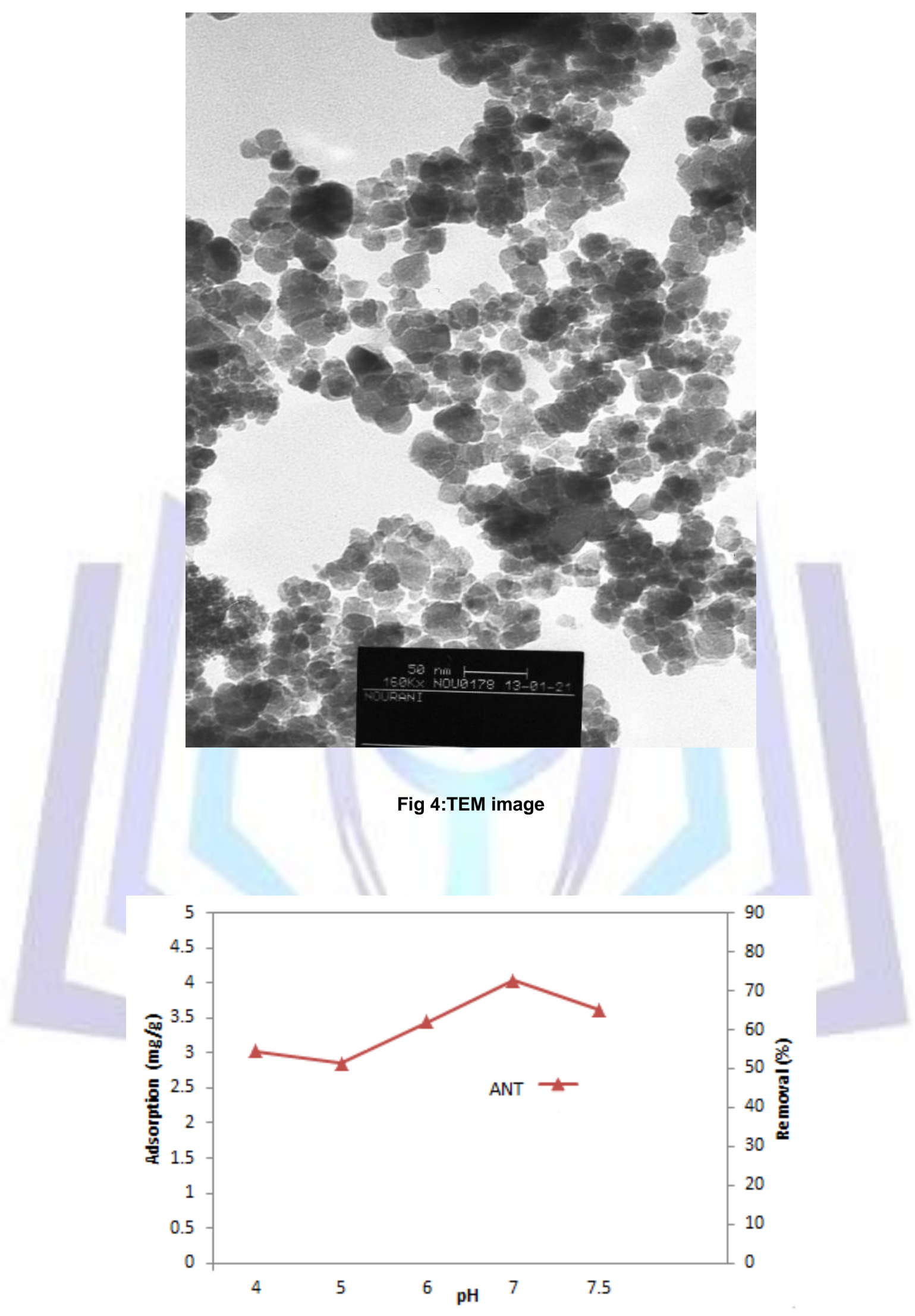

Fig 5:Effect of pH on adsorption of ANT on CGMMNPs 


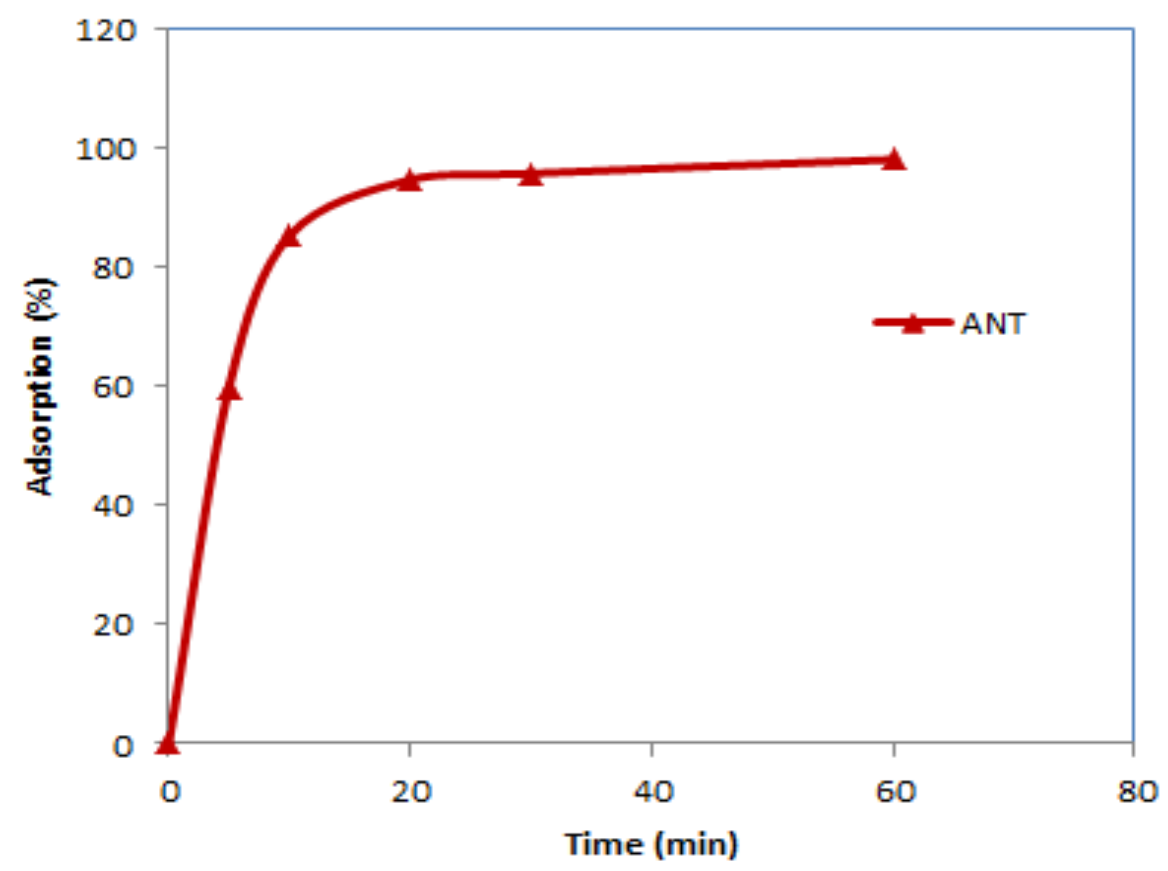

Fig 6: The kinetic study of ANT removal

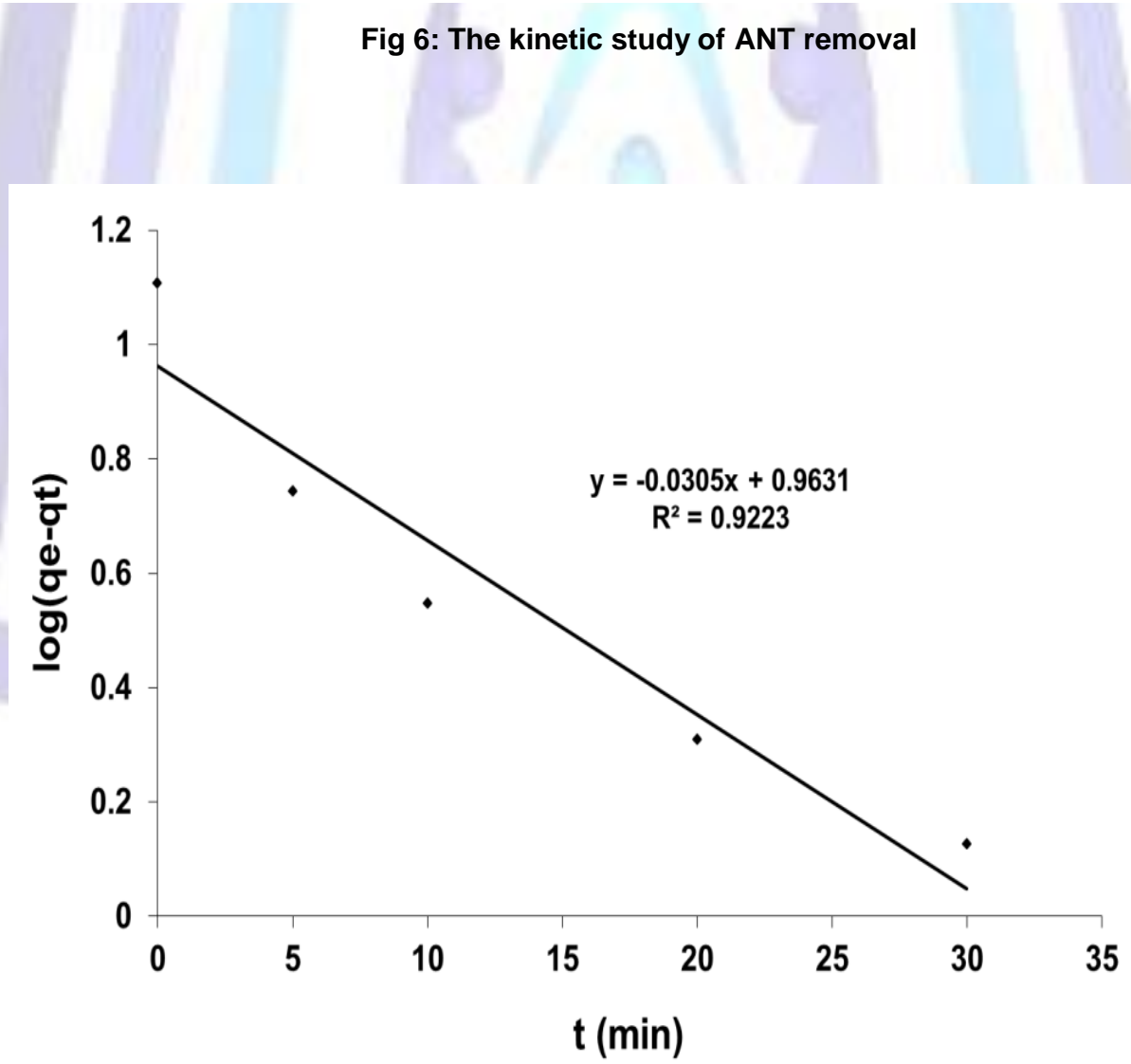

Fig 7:The pseudo - first -order kinetics for ANT adsorption by CGMMNPs 


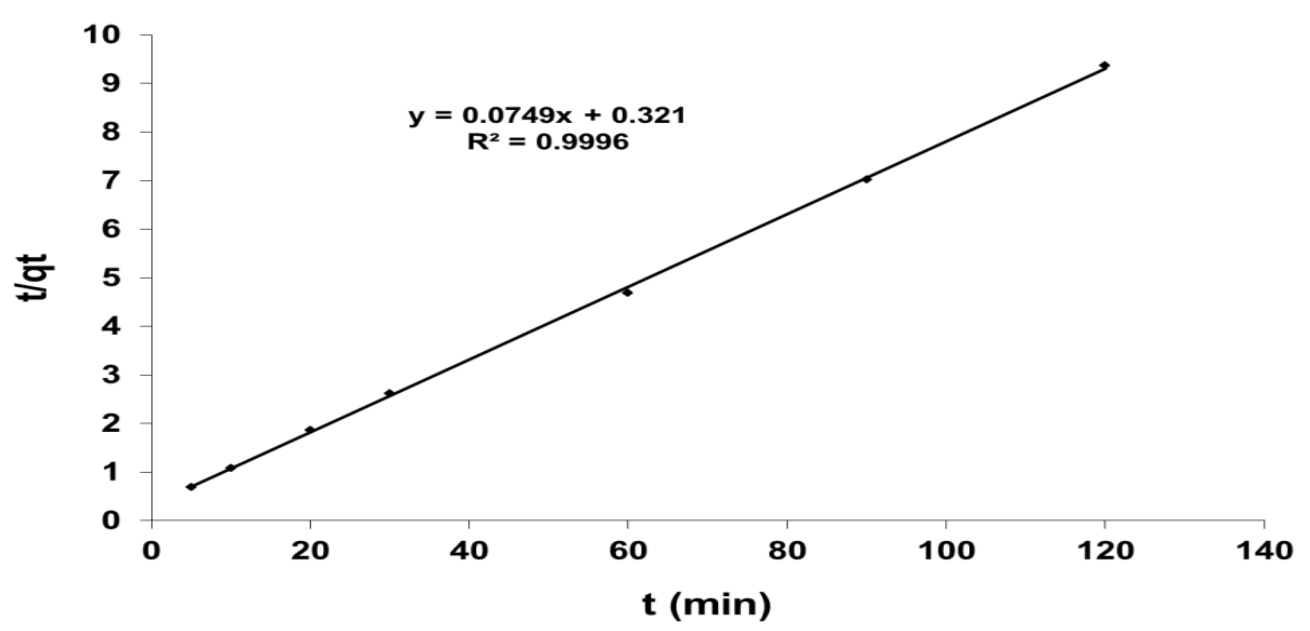

Fig 8:The pseudo-second-order kinetics for ANT adsorption by CGMMNPs

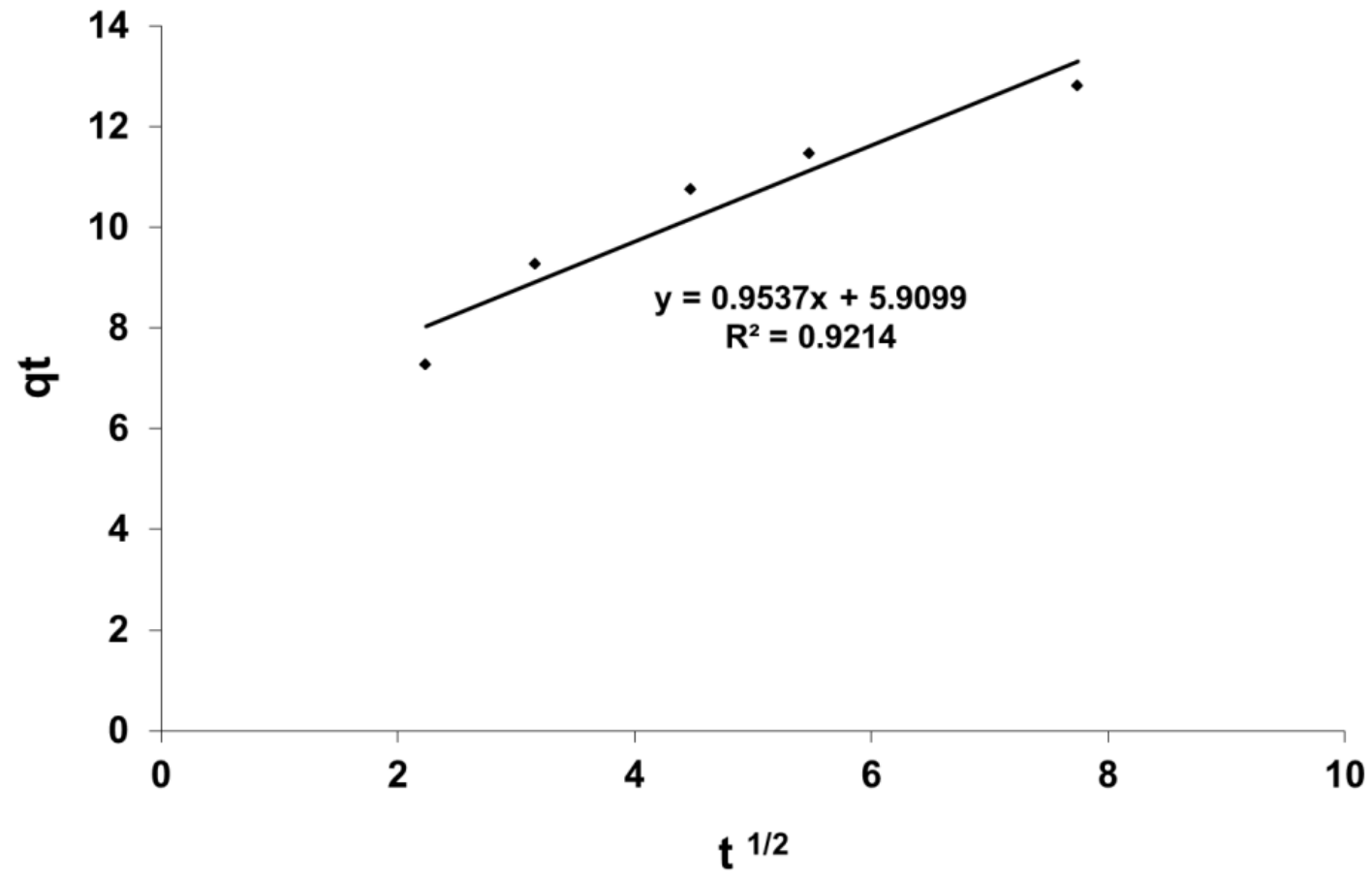

Fig 9:Intraparticle diffuision kinetics for ANT adsorption by CGMMNPs 
Kinetic Models

\begin{tabular}{|c|c|}
\hline \multicolumn{2}{|c|}{ pseudo-first-order } \\
\hline qe (mg/g) & 9.183 \\
\hline k1 & 0.070 \\
\hline $\mathbf{R}^{2}$ & 0.922 \\
\hline \multicolumn{2}{|c|}{ pseudo-second-order } \\
\hline qe (mg/g) & 13.35 \\
\hline K2 & 0.017 \\
\hline$R^{2}$ & 0.921 \\
\hline \multicolumn{2}{|c|}{ Intraparticle diffusion } \\
\hline$k p(\mathrm{mg} / \mathrm{g} \min 0.5)$ & 0.953 \\
\hline C & 5.909 \\
\hline $\mathbf{R}^{2}$ & 0.921 \\
\hline
\end{tabular}

Table 1: Comparison of the pseudo-first-order, pseudo-second-order and intraparticle|diffusion models calculated equilibrium, rate constants and correlation coefficients

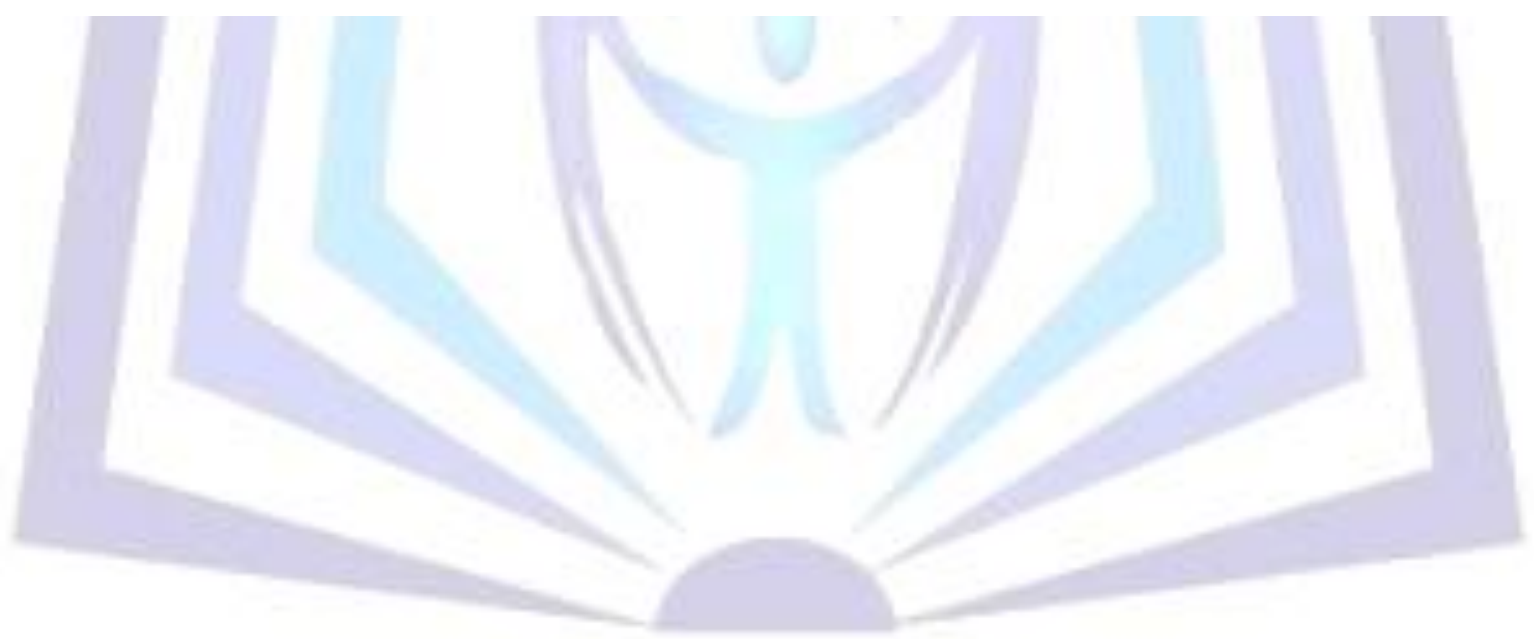

